\section{POSTBYPASS EFFECTS OF DELAYED REWARMING ON CEREBRAL BLOOD FLOW VELOCITIES IN INFANTS AFTER TOTAL CIRCULATORY ARREST}

Cerebral perfusion is reduced after prolonged periods of total circulatory arrest in infants. Methods of rewarming after arrest may modify the flow pattern of recovery, and a single report has suggested that using cold reperfusion to delay rewarming could mitigate abnormalities in cerebral blood flow. Cerebral perfusion was evaluated by transcranial Doppler sonography in 16 infants who required periods of total circulatory arrest of 35 minutes or more. In group A $(n=9)$ rewarming was begun immediately on reperfusion, whereas in group $B(n=7)$ a 10 -minute period of cold reperfusion was instituted before rewarming was begun. The mean and end-diastolic flow velocities were measured before incision (baseline) and at 20, 45, and 90 minutes after conclusion of cardiopulmonary bypass. Mean arterial pressure, hematocrit value, and arterial carbon dioxide tension were controlled, with no significant differences between the two groups $(p>0.05)$. In group $A$, the mean cerebral blood flow velocity was below the baseline level at all three postbypass measurements $(p<0.001)$. In group B, however, mean velocity did not differ significantly from the baseline value $(p>0.05)$. Twenty minutes after bypass, 89\% of the patients in group A had no diastolic Doppler signal, indicating absence of perfusion during diastole, compared with only $28 \%$ in group B ( $p=$ 0.02). These preliminary results suggest that a delay in rewarming on reperfusion may be beneficial in infants after circulatory arrest. ( $J$ THORAC CARDIOVASC SuRG 1995;110:1686-91)

Rosendo A. Rodriguez, MD, $\mathrm{PhD}^{\mathrm{a}}$ (by invitation), Erle H. Austin III, MD (by invitation), and Steve M. Audenaert, $\mathrm{MD}^{\mathrm{b}}$ (by invitation), Louisville, Ky. Sponsored by Laman A. Gray, Jr., MD, Louisville, Ky.
T otal circulatory arrest (TCA) during profoundly hypothermic cardiopulmonary bypass (CPB) has been used for the repair of complex congenital heart defects during pediatric cardiac surgery. However, evidence of abnormal cerebral perfusion, ${ }^{1}$ metabolism, ${ }^{2}$ and electrical activity ${ }^{3}$ in some infants after TCA raises concern that aspects of this technique may be involved in the neurologic dysfunction that is more common after TCA than after procedures done with CPB alone.

Transcranial Doppler sonography has shown that cerebral blood flow (CBF) velocity is reduced after $\mathrm{TCA}^{4,5}$ and this effect has been correlated with post-

From the Departments of Surgery ${ }^{a}$ and Anesthesiology, ${ }^{b}$ University of Louisville and Kosair Children's Hospital, Louisville, Ky.

Supported in part by a grant from the Children's Hospital Foundation, Louisville, Ky.

Read at the Seventy-fifth Annual Meeting of The American Association for Thoracic Surgery, Bosston, Mass., April 23-26, 1995.

Address for reprints: Erle H. Austin III, MD, Department of Surgery, University of Louisville, Louisville, KY 40292.

Copyright (c) 1995 by Mosby-Year Book, Inc.

$0022-5223 / 95 \$ 5.00+0 \quad \mathbf{1 2 / 6 / 6 8 7 4 0}$ ischemic hypoperfusion using direct measurements of CBF. ${ }^{1}$ Cerebral hypoperfusion first becomes evident during the period of rewarming. Reduced perfusion in a warmed brain may cause an unbalanced ratio between brain perfusion and metabolic demands. ${ }^{2}$ These physiologic consequences suggest that fast rewarming or excessive hyperthermia after TCA may not be beneficial to the brain, and perhaps gradual or stepwise rewarming may improve the balance between CBF and metabolism. A single report ${ }^{7}$ that a delay in rewarming after TCA modified the flow pattern of recovery suggested that a brief period of cold reperfusion could improve CBF in the early postbypass period. Our purpose was to determine whether delayed rewarming (cold reperfusion) after TCA has any beneficial effect on postbypass CBF velocity.

\section{Patients and methods}

Population sample. Sixteen infants requiring periods of TCA of 35 minutes or longer participated in this study. Patients were divided according to whether a 10-minute period of delay in rewarming (cold reperfusion) was used on 
reinstitution of $\mathrm{CPB}$. Patients were not randomized but were divided chronologically as we changed our pattern of rewarming to include a period of cold reperfusion. No other changes in surgical, anesthetic, or perfusion management occurred during the time frame of the study. Informed consent for transcranial Doppler monitoring was obtained from the parents of the infants included in this study.

In group $\mathrm{A}(n=9)$, rewarming began immediately with reperfusion. The water temperature of the heat exchanger was maintained at $5^{\circ}$ to $10^{\circ} \mathrm{C}$ above the patient's core temperature until a maximum perfusate temperature of $39^{\circ} \mathrm{C}$ was reached. During rewarming, CPB flow rates began at 50 to $70 \mathrm{ml} / \mathrm{kg}$ per minute and were increased as the infant's core temperature increased. At $28^{\circ} \mathrm{C}$ flow was typically 100 to $120 \mathrm{ml} / \mathrm{kg}$ per minute, and at $37^{\circ} \mathrm{C}$ flow was usually 150 to $170 \mathrm{ml} / \mathrm{kg}$ per minute before CPB was discontinued. In-line venous oxygen saturations were monitored continuously during rewarming and bypass flow was increased to maintain a level greater than $60 \%$.

Group B (cold reperfusion) consisted of seven infants for whom the blood temperature was maintained below $19^{\circ} \mathrm{C}$ (mean $17.1 \pm 1.2$ ) for 10 minutes after reinstitution of $\mathrm{CPB}$. Once this period was accomplished, rewarming was started in the same fashion as in group $\mathrm{A}$.

Anesthetic management. Drugs for premedication or induction (or both) consisted of ketamine and midazolam given orally or intravenously, or by both those methods. Additional anesthetic management consisted of loading doses of intravenous fentanyl (50 to $100 \mu \mathrm{g} / \mathrm{kg}$ ) and midazolam $(0.1$ to $0.2 \mathrm{mg} / \mathrm{kg}$ ) before incision followed by continuous infusion (midazolam, $50 \mu \mathrm{g} / \mathrm{kg}$ per hour, and fentanyl, $10 \mu \mathrm{g} / \mathrm{kg}$ per hour) or bolus doses of fentanyl and midazolam. Pancuronium and vecuronium were used as required for neuromuscular blockade. No volatile anesthetic agents were used during any part of the procedure.

CPB management. CPB was instituted by use of a single aortic cannula and one atrial cannula. Extracorporeal circulation was maintained with nonpulsatile pump flow with a membrane oxygenator (Cobe CPML, Cobe Laboratories, Inc., Denver, Colo). Hypothermia was attained by core cooling, a cold room, and ice bags on the head. Tympanic temperature measured the effects of variations in body temperature. Time of cooling from $35^{\circ} \mathrm{C}$ to the lowest temperature before TCA and time of rewarming from the final temperature at the end of TCA to $35.5^{\circ} \mathrm{C}$ were also measured. The lowest temperature before TCA was $16.8^{\circ} \pm$ $1.6^{\circ} \mathrm{C}$ for group $\mathrm{A}$ and $17^{\circ} \pm 1.2^{\circ} \mathrm{C}$ for group $\mathrm{B}$.

The pump priming solution was composed of electrolyte solutions (Normosol-R, Abbott Hospital Products, Abbott Park, Ill., or Plasma-Lyte A, Travenol Laboratories, Inc., Deerfield, Ill.), albumin (25\%), heparin 1000 to 5000 units in the total solution, sodium bicarbonate ( 25 to $30 \mathrm{mEq} / \mathrm{L}$ ), and packed red blood cells or fresh frozen plasma as necessary to maintain a hematocrit level between $20 \%$ and $25 \%$ during CPB. The alpha-stat regimen was used for management of arterial carbon dioxide tension $\left(\mathrm{PaCO}_{2}\right)$, maintaining levels between 35 and $40 \mathrm{~mm} \mathrm{Hg}$. Mean arterial pressure, transcutaneous peripheral oxygen saturation, end-tidal carbon dioxide, and central venous pressure were also continuously monitored. Arterial blood gases and hemoglobin and hematocrit values were determined before and after $\mathrm{CPB}$ and during CPB at the end of cooling.
Table I. Demographic and $C P B$ data

\begin{tabular}{lccc}
\hline & Group A & Group B & Mann-Whitney \\
\hline Age (days) & $58 \pm 136$ & $51 \pm 60$ & NS \\
Weight (kg) & $3.5 \pm 1.7$ & $3.5 \pm 1.2$ & NS \\
DHCA duration (min) & $58 \pm 29$ & $44 \pm 6$ & NS \\
CPB time (min) & $178 \pm 84$ & $151 \pm 66$ & NS \\
Crossclamp time (min) & $85 \pm 52$ & $61 \pm 48$ & NS \\
Time of cooling (min) & $25 \pm 5$ & $25 \pm 5$ & NS \\
Time of rewarming (min) & $34 \pm 9$ & $41 \pm 2$ & NS \\
\hline
\end{tabular}

$D H C A$, Deep hypothermic circulatory arrest; $N S$, not significant.

Dobutamine (5 to $10 \mu \mathrm{g} / \mathrm{kg}$ per minute), dopamine (5 to $20 \mu \mathrm{g} / \mathrm{kg}$ per minute), epinephrine (0.16 to $0.2 \mu \mathrm{g} / \mathrm{kg}$ per minute), or oxymetazoline (Neo-Synephrine, $0.16 \mu \mathrm{g} / \mathrm{kg}$ per minute) was begun just before or just after termination of $\mathrm{CPB}$ in five patients within each group. Three patients (one in group A) required the addition of amrinone (10 to $12 \mu \mathrm{g} / \mathrm{kg}$ per minute), and a single patient in group $B$ received a combination of nitroprusside $(0.5$ $\mu \mathrm{g} / \mathrm{kg}$ per minute) and nitroglycerin $(2.5 \mu \mathrm{g} / \mathrm{kg}$ per minute). Inotropic support was dictated by patient condition and did not differ significantly between groups.

Transcranial Doppler echocardiography. Mean integrated CBF velocities of the last five cardiac cycles were continuously measured with a $2 \mathrm{MHz}$ transcranial Doppler probe (Medasonics Inc., Fremont, Calif.) aimed at the M1 segment of the right middle cerebral artery by way of the right temporal window. The lowest averaged frequency values of the Doppler waveform were used to calculate the end-diastolic flow velocities. An angle of 0 degrees was assumed. Probe and patient position were finalized and probe position was fixed and then protected by a metal frame. Care was taken to prevent patient or probe movement throughout the study period. Initial measurements were obtained before incision during stable anesthetic and hemodynamics conditions and were defined as control baseline. Additional measurements were recorded at 20,45, and 90 minutes after the end of CPB.

Data analysis. So that interindividual differences and age effects on transcranial Doppler velocities could be reduced, absolute values were transformed to relative values, expressed as percentages of individual baselines. Nonparametric tests including Kruskal-Wallis, MannWhitney, and Fisher's exact test were used to determine significance in the comparisons. Differences were regarded as significant if the $p$ value was less than 0.05 .

\section{Results}

Demographic and bypass data are indicated in Table I and surgical procedures are indicated in Table II. Age, weight, and CPB variables were not significantly different between groups (Mann-Whitney, $p>0.05$ ).

Fig. 1 shows the mean CBF velocities measured at 20, 45, and 90 minutes after $C P B$ was discontinued. The mean CBF velocity remained below the baseline $(p<0.001)$ in the group having immediate rewarming (group A), but for the group with a delay 


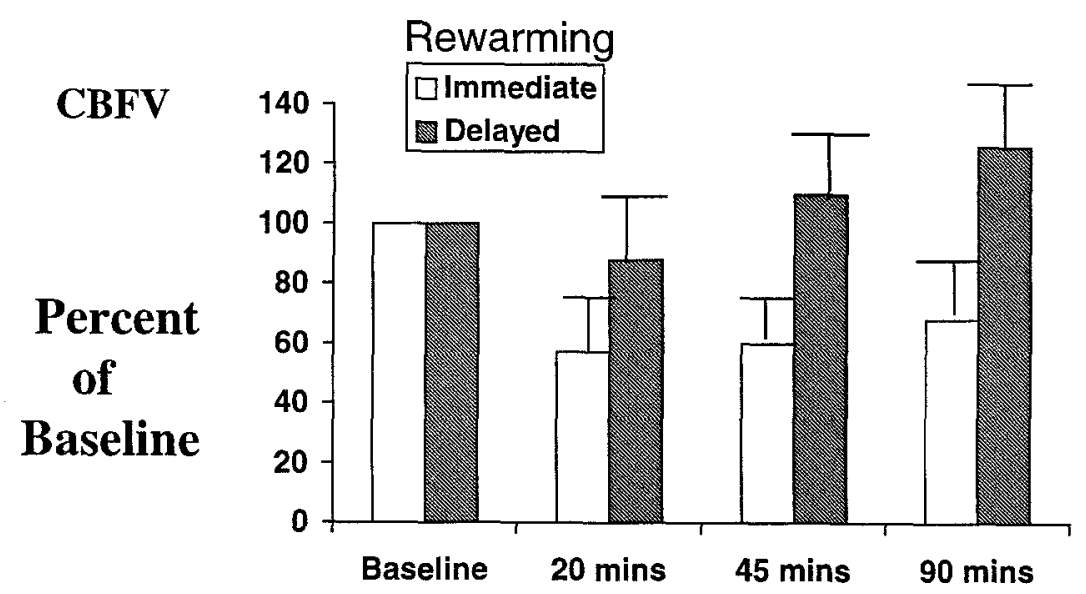

\section{Postbypass}

Fig. 1. Mean cerebral blood flow velocities $(C B F V)$ expressed in percentages of baseline for groups $\mathrm{A}$ (immediate) and B (delayed). Flow velocities remained below the baseline in group A $(p<0.001)$, but for group B mean velocity was comparable with baseline $(p>0.05)$ at all postbypass measurements.

Table II. Surgical procedures

\begin{tabular}{lcc}
\hline \multicolumn{1}{c}{ Procedures } & Group A & Group $B$ \\
\hline Hemi-Fontan & 1 & 2 \\
Norwood procedure & 2 & 0 \\
Truncus arteriosus repair & 2 & 1 \\
TOF repair & 0 & 1 \\
VSD repair & 1 & 3 \\
TAPVR & 1 & 1 \\
Bidirectional Glenn shunt & 0 & 1 \\
Arterial switch & 0 & 1 \\
Damus procedure & 1 & 0 \\
Heart transplant & 1 & 0
\end{tabular}

TOF, Tetralogy of Fallot; $V S D$, ventricular septal defect; TAPVR, total anomalous pulmonary venous return.

in rewarming (group B), mean CBF velocity was comparable with baseline $(p>0.05)$. Ninety minutes after $\mathrm{CPB}$, the average mean $\mathrm{CBF}$ velocity was $68 \% \pm 17 \%$ in group $\mathrm{A}$ as compared with $126 \% \pm$ $50 \%$ in group B.

Analysis of end-diastolic CBF velocity showed that at 20 minutes after bypass, $89 \%$ of the patients with immediate rewarming had no diastolic Doppler signal, which indicates absence of perfusion during diastole, as compared with only $28 \%$ in the group with cold reperfusion (Fisher's exact test, $p=0.02$ ). At 45 and 90 minutes after bypass, the diastolic signal was absent in $56 \%$ of the patients with immediate rewarming compared with none in the group with cold reperfusion (Fisher's exact test, $p=$ 0.03 ). In addition, six patients with delayed rewarming and only two patients with immediate rewarming had diastolic flow velocities equal to or greater than baseline at the final measurement. Fisher's exact test indicated a significant difference between the two groups $(p=0.02)$.

Mean arterial pressure, $\mathrm{PaCO}_{2}$, and hematocrit values were not significantly different $(p>0.05)$ between groups in the prebypass, bypass, or postbypass phases. Postbypass mean arterial pressures were comparable with baseline values (KruskalWallis, $p>0.05$ ) (Fig. 2), and management of $\mathrm{PaCO}_{2}$ was maintained relatively constant throughout the procedure (Kruskal-Wallis, $p>0.05$ ). The hematocrit value decreased as expected during $\mathrm{CPB}$, remaining low after CBP was discontinued $(p<0.01)$

\section{Discussion}

Despite the frequent use of profound hypothermia and TCA in the repair of complex congenital heart defects in children, TCA imposes a risk of neurologic injury. ${ }^{8,9}$ To detect the mechanisms associated with brain injury, investigative efforts have been directed at determining the effects of hypothermia and TCA on $\mathrm{CBF}^{1}$ and metabolism. ${ }^{2} \mathrm{Al}-$ though measurements of neurologic outcome in young infants have been difficult to characterize and quantitate, postoperative seizures ${ }^{3}$ and some long- 
term cognitive effects ${ }^{10}$ have been more prevalent after TCA than after procedures done with CPB alone.

Transcranial Doppler sonography has been used to characterize episodes of hypoperfusion after TCA and to evaluate efforts to improve brain perfusion during cardiac operations in children. ${ }^{7} \mathrm{~A}$ recent publication by Astudillo and associates ${ }^{7}$ describing transcranial Doppler measurements in infants undergoing hypothermic CPB revealed that periods of TCA resulted in a postbypass CBF pattern distinguished by the absence of a Doppler signal during diastole. This finding contrasted with the presence of postbypass diastolic perfusion in patients not subjected to a period of TCA. In addition, they observed that the only two patients in their TCA group with intact postbypass diastolic flow had undergone reperfusion with a cold perfusate for 10 to 20 minutes before rewarming had begun. The purpose of the present study was to test the validity of their observation by intentionally applying a prescribed period of cold reperfusion to a group of infants undergoing TCA.

In this nonrandomized study we compared the effects of TCA on CBF velocity in two groups of infants undergoing periods of TCA of 35 minutes or more. One group received the conventional reperfusion strategy of immediate rewarming, whereas the second group was exposed to a 10-minute period of cold reperfusion before rewarming was initiated. The two groups were comparable with regard to demographics, bypass features, $\mathrm{PaCO}_{2}$, and hematocrit management.

Consistent with previous reports, ${ }^{5,7}$ postbypass CBF velocity was reduced in the group with immediate rewarming. In the group undergoing cold reperfusion, however, postbypass $\mathrm{CBF}$ velocity was not different from baseline. The differences in flow velocity were most striking when diastolic flow was analyzed. Recovery of a diastolic Doppler signal was more common after cold reperfusion than after immediate rewarming. These differences could not be attributed to mean arterial pressure, $\mathrm{PaCO}_{2}$, or hematocrit value. Inotropic management had clear effects on mean arterial pressure and had related effects on systolic CBF velocity, but had no discernible effects on end-diastolic CBF velocity.

The mechanism of this phenomenon cannot be elucidated from this study. The decreased CBF after arrest indicates that the vascular resistance of the brain and the intracranial pressure ${ }^{11}$ are increased after separation from CPB. An increase in cerebral

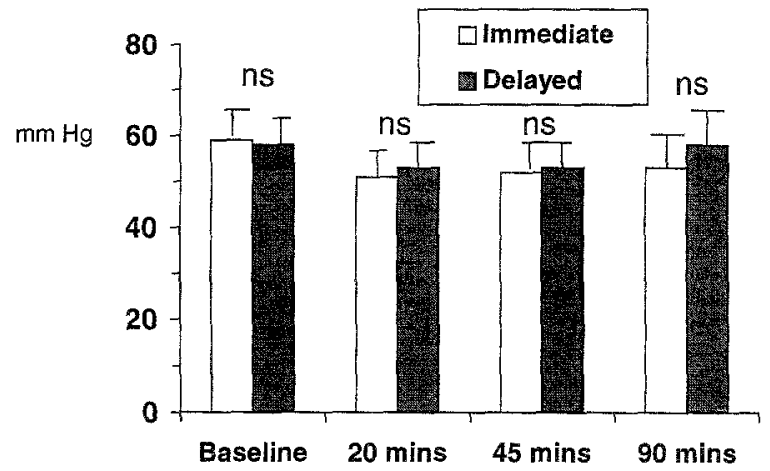

Fig. 2. Mean arterial pressures for groups A (immediate) and $\mathrm{B}$ (delayed) at baseline and at 20, 45, and 90 minutes after bypass. No significant differences ( $n s)$ were detected between the two groups at any measurement $(p>0.05)$.

vascular tone may be due to an incomplete clearing of metabolites accumulated during the period of arrest. A brief period of cold reperfusion may permit clearance of these metabolites before additional metabolic products are derived from a rewarming brain. An animal preparation during which intracranial pressure, brain tissue $\mathrm{pH}$, oxygen tension, and carbon dioxide tension can be measured may provide insight into the improvement in CBF that occurs when cold reperfusion is applied after TCA.

Limitations of the present study include its lack of randomization, the small sample sizes, slight disparity between groups for duration of TCA, and the failure to measure other indicators of brain function and metabolism. As a preliminary observation, however, the two groups are relatively well matched and the differences noted are significant. Measurements of cerebral metabolism, creatine kinase BB isoenzyme, and cerebral lactate release should be included in future studies of cold reperfusion after TCA.

\section{REFERENCES}

1. Greeley WJ, Ungerleider RM, Smith LR, Reves JG. The effects of deep hypothermic cardiopulmonary bypass and total circulatory arrest on cerebral blood flow in infants and children. J THORAC CARDrovasC SuRg 1989;97:737-45.

2. Greeley WJ, Kern FH, Ungerleider RM, et al. The effect of hypothermic cardiopulmonary bypass and total circulatory arrest on cerebral metabolism in neonates, infants, and children. J THORAC CARDIOVASC SURG 1991;101:783-94.

3. Newburger JW, Jonas RA, Wernovsky $G$, et al. A comparison of the perioperative neurologic effects of hypothermic circulatory arrest versus low-flow cardio- 
pulmonary bypass in infant heart surgery. $\mathrm{N}$ Engl $\mathrm{J}$ Med 1993;329:1057-64.

4. Lundar T, Lindberg H, Lindegaard K-F, et al. Cerebral perfusion during major cardiac surgery in children. Pediatr Cardiol 1987;8:161-5.

5. Hillier SC, Burrows FA, Bissonnette B, Taylor RH. Cerebral hemodynamics in neonates and infants undergoing cardiopulmonary bypass and profound hypothermic circulatory arrest: assessment by transcranial Doppler sonography. Anesth Analg 1991; 72:723-8.

6. Ekroth R, van der Linden J, Lincoln C, Scallan M. Cerebral perfusion and metabolism after profound hypothermia-comparison between procedures involving no flow and low flow. Cardiol Young 1993;3: $378-82$.

7. Astudillo R, van der Linden J, Ekroth R, et al. Absent diastolic cerebral blood flow velocity after circulatory arrest but not after low flow in infants. Ann Thorac Surg 1993;56:515-9.

8. Ferry PC. Neurologic sequelae of open-heart surgery in children: an "irritating question." Arch Pediatr Adolesc Med 1990;144:369-73.

9. Newburger JW, Silbert AR, Buckley LP, Fyler DC. Cognitive function and age at repair of transposition of the great arteries in children. $\mathrm{N}$ Engl $\mathbf{J}$ Med 1984:310:1495-9.

10. Wells FC, Coghill S, Caplan HL, Lincoln C. Duration of circulatory arrest does influence the psychological development of children after cardiac operation in early life. J THORAC CARDIOVASC SuRg 1983;86:823-31.

11. Friesen $\mathrm{RH}$, Thieme R. Changes in anterior fontanel pressure during cardiopulmonary bypass and hypothermic circulatory arrest in infants. Anesth Analg 1987;66:94-6.

\section{Discussion}

Dr. Ross M. Ungerleider (Durham, N.C.). This study may stimulate development of another technique in the evolution of numerous methods to protect the patient from hypothermic circulatory arrest. Increasing laboratory and clinical data support numerous methodologic changes in the way hypothermic circulatory arrest is used. The summed effect of these many technical refinements will be to produce systems of cerebral protection paralleling those that were developed when efforts were focused on improving myocardial protection.

There are four phases of CPB that can affect ultimate neurologic outcome. The first is the cooling phase. From numerous studies we now believe that it is better to cool the brain for at least 20 minutes before arrest, to cool to temperatures colder than the conventionally recommended $18^{\circ} \mathrm{C}$ (and maybe to temperatures below $15^{\circ} \mathrm{C}$ ), to consider using $\mathrm{pH}$-stat cooling in certain circumstances to improve cerebral cooling, and to avoid the use of circulatory arrest when cooling patterns are abnormal. The second phase is the arrest phase itself. Both laboratory and clinical data from our group have demonstrated a benefit from packing the head in ice. Although not yet clinically available, pharmacologic agents such as "cerebroplegia" and/or the use of neuroexcitatory amino acid blockade with various nitrosodimethylamine blockers may be available for clinical use soon to protect against prolonged durations of circulatory arrest.

Previous studies from our group and others have demonstrated the effectiveness of intermittent perfusion of the brain. The most effective method to limit brain injury during the arrest period is probably for surgeons to use arrest only when necessary during the operation and thereby limit its overall duration.

I will skip the third phase for the moment. The fourth phase is after CPB. Dr. Randall Griepp and his colleagues have made us aware that the brain is vulnerable to injury during this time unless adequate cardiac output and cerebral oxygen delivery are maintained. Last year at this meeting our group presented results that suggested a beneficial impact of modified ultrafiltration after bypass on cerebral metabolic recovery after circulatory arrest. We are currently completing a prospective randomized clinical study on this subject.

Dr. Austin, your study has focused on the third phase of bypass, reperfusion after circulatory arrest. To date, few interventions have been shown to be helpful in improving cerebral recovery during this phase. We do know from adult bypass data, however, that neurologic outcome is worse for those patients whose brains are rewarmed too aggressively after hypothermic bypass even without circulatory arrest. This problem can be avoided by careful rewarming. Your study is intriguing but raises the following questions.

First, extracranial Doppler sonography is a limited technique. It measures blood flow velocity in large vessels but does not indicate regional flow or, more important, metabolism. I am sure this limitation is one that you fully recognize, but it does serve to make us cautious in interpreting your findings.

Second, although the difference was not statistically significant, the group with delayed rewarming had a much shorter period of circulatory arrest than the group with immediate rewarming. In our clinical data, which we continue to accumulate, we have noticed that 44 minutes of circulatory arrest, as shown by your patients with delayed rewarming, especially if many of the refinements mentioned are used, may not produce significant patterns of metabolic injury. This is not as often the case for patients with circulatory arrest periods as long as 58 minutes. Could your observations be influenced in part by this difference between our groups? Finally, what mechanism do you suspect is responsible for this observation? Is it possible that our findings reflect inappropriate methods of rewarming in the immediate group as opposed to the beneficial effects from 10 minutes of cold reperfusion? What were your typical pump flow rates and temperature gradients during rewarming?

Despite these criticisms, you have described a simpleto-apply technique that may further improve neurologic outcome after circulatory arrest. We would be delighted to collaborate with you on a controlled laboratory inves- 
tigation of this technique so that we could further inform our colleagues regarding this matter in the near future.

Dr. Austin. I acknowledge that other techniques using xenon washout may give a better measure of true $\mathrm{CBF}$ than does the Doppler technique. Transcranial Doppler sonography, however, is a simple technique that everybody can use, and it does give continuous data, which the other techniques do not. In fact, the key finding in the study that stimulated us to embark on this particular investigation was the absence of flow during diastole after circulatory arrest. The absence of a Doppler signal during diastole is the key feature that other techniques cannot show.

With regard to the circulatory arrest times, Astudillo and associates noted the absence of flow during diastole in patients with circulatory arrest times as short as 20 minutes. This may be just a very sensitive technique for identifying a problem with $\mathrm{CBF}$ after circulatory arrest. It may be so sensitive that the problem does not have a clinical correlation. Nevertheless, I think the Doppler technique is a sensitive indicator that may help to improve management of patients requiring a period of circulatory arrest.

Our flow rates on rewarming are a little bit higher than they are during cooling. We start rewarming at a flow rate of $50 \mathrm{ml} / \mathrm{kg}$ per minute. At $28^{\circ} \mathrm{C}$ the rate is about 100 $\mathrm{ml} / \mathrm{kg}$ per minute, and before $\mathrm{CPB}$ is ended the flow rate is usually 150 to $170 \mathrm{ml} / \mathrm{kg}$ per minute, sometimes higher. We keep the gradient less than $10^{\circ} \mathrm{C}$ while rewarming.

Our data are not sufficient to determine the mechanism for this observation. A well-controlled laboratory study may shed some light on the mechanism. My guess is that rewarming the brain in the presence of metabolites that have collected during circulatory arrest adversely affects CBF. It is possible that a short period of cold reperfusion allows some of those metabolites to wash out before additional metabolites are derived from a rewarming brain.

Mr. Christopher R. Lincoln (London England). The hypothesis that delay in rewarming after profound hypothermia and circulatory arrest may be beneficial was noted in the study of Astudillo and Van der Linden when researching CBF velocity after cardiac surgery in my patients. The audience may be interested to know how we stumbled on this finding and suggested the hypothesis.

On resumption of CPB in two patients, Van der Linden noticed an intermittent but marked change in the diastolic blood flow velocity profile of the Doppler signal. Unknown to him, I was coincidentally venting the ascending aorta through a fairly generous hole to remove air. Because of his difficulty in stabilizing, the signal 1 serendipitously continued with hypothermic CPB in these two patients, thereby delaying rewarming for between 10 and 20 minutes. These two patients who had profound hypothermia and circulatory arrest had a complete diastolic blood flow velocity signal similar to the control group of patients who had hypothermic low-flow CPB. In contrast, the remaining 10 patients who had profound hypothermic circulatory arrest had absence of the diastolic blood flow velocity profile. On a cautionary note, it may be that the act of removing air through an ascending aortic vent in infants and young children could have an important possibly deleterious effect on CBF.

Dr. Richard A. Jonas (Boston, Mass.). I believe this work has been further validated. When I reviewed this abstract-and these abstracts are reviewed blind for the AATS-I was sure this article must be from Columbia, because Amy Jonassen, who does the transcranial Doppler studies there, had recently reported exactly the same findings at a brain meeting. It thus appears that this may be a real phenomenon. Perhaps the mechanism relates to John Mayer's work with myocardial reperfusion with high pressure versus low pressure. It may be telling us something about endothelial injury in the early reperfusion phase when the endothelium perhaps is particularly vulnerable to injury. 